\title{
Analysis of in vitro ADCC and clinical response to trastuzumab: possible relevance of Fc $\gamma$ RIIIA/Fc $\gamma$ RIIA gene polymorphisms and HER-2 expression levels on breast cancer cell lines
}

\author{
Silvia Boero ${ }^{1 \dagger}$, Anna Morabito ${ }^{2 \dagger}$, Barbara Banelli ${ }^{2}$, Barbara Cardinali ${ }^{3}$, Beatrice Dozin ${ }^{4}$, Gianluigi Lunardi ${ }^{5}$, \\ Patrizia Piccioli ${ }^{6}$, Sonia Lastraioli ${ }^{7}$, Roberta Carosio ${ }^{2}$, Sandra Salvi ${ }^{8}$, Alessia Levaggi ${ }^{3}$, Francesca Poggio ${ }^{9}$, \\ Alessia D’Alonzo ${ }^{3}$, Massimo Romani ${ }^{2}$, Lucia Del Mastro ${ }^{3}$, Alessandro Poggi ${ }^{1 \dagger}$ and Maria Pia Pistillo ${ }^{2^{*}}$
}

\begin{abstract}
Background: Trastuzumab is a humanized monoclonal antibody $(\mathrm{mAb})$ currently used for the treatment of breast cancer (BC) patients with HER-2 overexpressing tumor subtype. Previous data reported the involvement of Fc $\gamma R$ RIIIA/IIA gene polymorphisms and/or antibody-dependent cellular cytotoxicity (ADCC) in the therapeutic efficacy of trastuzumab, although results on these issues are still controversial. This study was aimed to evaluate in vitro the functional relationships among FcyRIIIA/IIA polymorphisms, ADCC intensity and HER-2 expression on tumor target cells and to correlate them with response to trastuzumab.

Patients and methods: Twenty-five patients with HER-2 overexpressing BC, receiving trastuzumab in a neoadjuvant

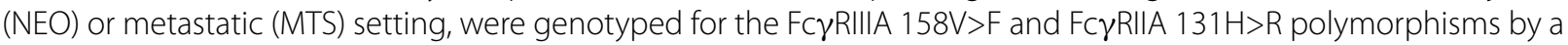
newly developed pyrosequencing assay and by multiplex Tetra-primer-ARMS PCR, respectively. Trastuzumab-mediated ADCC of patients' peripheral blood mononuclear cells (PBMCs) was evaluated prior to therapy and measured by ${ }^{51}$ Chromium release using as targets three human BC cell lines showing different levels of reactivity with trastuzumab.

Results: We found that the Fc $\gamma$ RIIIA $158 \mathrm{~F}$ and/or the FcyRIIA 131R variants, commonly reported as unfavorable in BC, may actually behave as ADCC favorable genotypes, in both the NEO ( $P$ ranging from 0.009 to 0.039 and from 0.007 to 0.047 , respectively) and MTS ( $P$ ranging from 0.009 to 0.032 and $P=0.034$, respectively) patients. The ADCC intensity was affected by different levels of trastuzumab reactivity with BC target cells. In this context, the MCF-7 cell line, showing the lowest reactivity with trastuzumab, resulted the most suitable cell line for evaluating ADCC and response to trastuzumab. Indeed, we found a statistically significant correlation between an increased frequency of patients showing ADCC of MCF-7 and complete response to trastuzumab in the NEO setting $(P=0.006)$.
\end{abstract}

Conclusions: Although this study was performed in a limited number of patients, it would indicate a correlation of FcyR gene polymorphisms to the ADCC extent in combination with the HER-2 expression levels on tumor target cells

*Correspondence: mariapia.pistillo@hsanmartino.it

†Silvia Boero, Anna Morabito and Alessandro Poggi equally contributed to the manuscript

${ }^{2}$ Unit of Tumor Epigenetics, IRCCS AOU San Martino-IST, Genoa, Italy

Full list of author information is available at the end of the article 
in $\mathrm{BC}$ patients. However, to confirm our findings further experimental evidences obtained from a larger cohort of $\mathrm{BC}$ patients are mandatory.

Keywords: FcyR single nucleotide polymorphisms, ADCC, Trastuzumab, Breast cancer patients

\section{Background}

Leukocyte $\mathrm{Fc} \gamma$ receptors (Fc $\gamma \mathrm{Rs}$ ) are structurally related glycoproteins belonging to the immunoglobulin (Ig) superfamily, which bind the fragment $\mathrm{C}(\mathrm{Fc})$ region of IgG leading to $\mathrm{Fc} \gamma \mathrm{R}$ aggregation at the cell surface and cell activation [1]. Fc $\gamma$ Rs are divided into 3 groups, Fc $\gamma$ RI (CD64), Fc $\gamma$ RII (CD32) and Fc $\gamma$ RIII (CD16) and subclasses, depending on their structural and functional properties. Fc $\gamma$ RI and Fc $\gamma$ RII are expressed mainly by monocytes and macrophages, whereas Fc $\gamma$ RIII is expressed by subsets of $\mathrm{T}$ cells and natural killer cells [2].

The most important function of the Fc $\gamma$ Rs is the regulation of the immune response as, upon their engagement, they can either stimulate or inhibit immune cell activation [2], suggesting that they can have a biological significance in the outcome of antibody-based therapies in tumors.

Among the functions mediated by activatory Fc $\gamma$ Rs, the antibody-dependent cellular cytotoxicity (ADCC), mediated by cells of the innate immunity, certainly plays an important role as it can contribute to eliminate tumor cells and, in some tumors, it may even represent the predominant effector of cell killing [3-6].

In the immunotherapy of HER-2 overexpressing $\mathrm{BC}$, trastuzumab monoclonal antibody $(\mathrm{mAb})$ may elicit ADCC upon binding to the HER-2 antigen region on tumor cells and with the Fc region to Fc $\gamma$ Rs on immune effector cells $[7,8]$. This mechanism is similar to that of other mAbs of the IgG1 isotype, such as rituximab and cetuximab, upon binding to CD20 and EGFR, respectively [9-12]. Such an interaction triggers the immune cell degranulation and activation, resulting in the lysis of antibody coated target cells.

However, only 20-30 \% of HER-2-overexpressing patients respond to trastuzumab and a significant proportion of them become resistant to the mAb [13].

The extent of in vitro ADCC of BC cells mediated by trastuzumab may be influenced by several factors including single nucleotide polymorphisms ( $S N P S)$ in the $\mathrm{Fc} \gamma \mathrm{R}$ genes. It has been reported that these SNPS can alter the Fc $\gamma \mathrm{R}$ binding to the therapeutic mAbs and consequently the ADCC degree. In particular, the SNP rs396991 (G>T) corresponding to the substitution of valine $(\mathrm{V})$ with phenylalanine (F) at aminoacid position 158 of Fc $\gamma$ RIIIA $(158 \mathrm{~V}>\mathrm{F}$ variant) and the SNP rs1801274 (A >G) corresponding to the substitution of histidine $(\mathrm{H})$ with arginine (R) at aminoacid position 131 of Fc $\gamma$ RIIA $(131 \mathrm{H}>\mathrm{R}$ variant), appear to reduce the binding to the mAbs [14-16].

However, the association between $\mathrm{Fc} \gamma \mathrm{R}$ polymorphisms and trastuzumab efficacy in BC is controversial. Indeed, the homozygous Fc $\gamma$ RIIIA158V/V and Fc $\gamma$ RIIA $131 \mathrm{H} / \mathrm{H}$ phenotypes (commonly identified as $158 \mathrm{~V} / \mathrm{V}$ and $131 \mathrm{H} / \mathrm{H}$ genotypes) have been associated with ADCC, response to trastuzumab and progression-free survival in two small retrospective studies [7, 17], whereas a larger study did not support these findings [18].

In the present study, we have investigated the Fc $\gamma$ RIIIA158V $>$ F and Fc $\gamma$ RIIA131H $>$ R genotype frequencies in patients with BC overexpressing HER-2 and their role in the extent of in vitro trastuzumab-dependent lysis of HER2-positive BC cells. We demonstrate that PBMCs from BC patients carrying the Fc $\gamma$ RIIIA158F genotype can induce, in some circumstances, a more efficient ADCC response than PBMCs carrying the homozygous Fc $\gamma$ RIIIA $158 \mathrm{~V} / \mathrm{V}$ genotype. We also demonstrate that the ADCC associated to particular Fc $\gamma$ RIIIA and Fc $\gamma$ RIIA genotypes can be influenced by the HER-2 expression levels on target cells. In this context MCF7, a BC cell line showing the lowest HER-2 expression level, allowed us to point out a correlation between genotypes and ADCC, as well as between ADCC and patient response to trastuzumab.

\section{Methods}

\section{Patients}

Women with histological diagnosis of locally advanced invasive or metastatic $\mathrm{BC}$ were considered eligible for the study if classified as HER-2 positive, i.e. score $3+$ (by immuno-histochemical analysis: IHC) or IHC score $2+$ and FISH (fluorescence in situ hybridization) amplified. Twenty-five BC patients were enrolled in the study: 15 patients in the neo-adjuvant setting (NEO) and 10 patients in the metastatic setting (MTS).

In the NEO setting, all patients (with the exclusion of 1 treated only with paclitaxel) were treated with FEC (fluorouracil, epirubicin and cyclophosphamide) for 4 cycles followed by weekly paclitaxel for 12 weeks in combination with trastuzumab. In the MTS setting, patients underwent a first line chemotherapy in combination with trastuzumab.

Response to trastuzumab was evaluated on the basis of clinical, pathological and radiologic examination of the tumor before and after treatment. In details, for the NEO 
patients, pathological complete response (pCR) was used to evaluate the treatment response. $\mathrm{pCR}$ was assigned in absence of invasive residual carcinoma in the breast and/or at axillary lymph node level after surgery. In the presence of residual invasive carcinoma the response was considered partial (pPR). For the MTS patients, the revised RECIST criteria (version 1.1) were used to evaluate the treatment response which was classified as stable disease (SD), partial response (PR), complete response $(\mathrm{CR})$ and disease progression (PD).

This study was approved by the Ethics Committee of IRCCS AOU San Martino-IST, Genoa, Italy and written informed consent was obtained from each patient.

Thirty-three unrelated healthy Italian women (Transfusion Service, Galliera Hospital, and IRCCS AOU San Martino-IST, Genoa, Italy), matched for patient's age, were also included as a control population, upon written informed consent. In addition, a cohort of 64 unselected healthy donors were analyzed for Fc $\gamma$ RIIIA and Fc $\gamma$ RIIA genotyping and ADCC.

\section{Genotyping of FcyRIIIA 158V >F and FcyRIIA 131H $>R$ polymorphisms}

Genotyping of Fc $\gamma$ RIIIA 158V $>$ F (rs396991) and Fc $\gamma$ RIIA $131 \mathrm{H}>\mathrm{R}$ (rs1801274) variants was performed on genomic DNA by multiplex Tetra-Primer Amplification Refractory Mutation System (T-ARMS) PCR, direct sequencing (SBT) and pyrosequencing (PSQ). Genomic DNA was extracted from peripheral blood mononuclear cells (PBMCs) using a conventional proteinase $\mathrm{K}$ protocol, as previously described [19].

The Fc $\gamma$ RIIIA was analyzed by PSQ and due to the high homology of Fc $\gamma$ RIIIA with Fc $\gamma$ RIIIB in the genomic region of interest, DNA samples were first amplified by primer pair specifically designed for it. To this aim, the PCR reaction was performed in a final volume of $20 \mu \mathrm{l}$ containing $\approx 25 \mathrm{ng}$ genomic DNA, $1.5 \mathrm{mM} \mathrm{Mg}{ }^{2+}$ (5x buffer A and buffer B), $200 \mu$ moli/L dNTPs, $0.8 \mu \mathrm{L}$ Elongase $^{\circledR}$ Enzyme Mix (Life Technologies) and $0.5 \mu \mathrm{mol} / \mathrm{L}$ of each primers (Table 1 ).

PCR products were analyzed on $1 \%$ agarose gel containing Eurosafe Nucleic Acid Stain (EuroClone, Milan, Italy) and the remaining amount was purified and diluted 1:20; then, to confirm specificity of Fc $\gamma$ RIIIA amplification, a short amplicon was analyzed by direct sequencing (using the Fc $\gamma$ RIIIA-F and Fc $\gamma$ RIIIA-R-S primers (Table 1).

For the PSQ assay, a nested-PCR was setup by amplifying $1 \mu \mathrm{l}$ of diluted PCR products with the primer pair designed using the Pyrosequencing Assay Design software (Biotage, Uppsala, Sweden) (Table 1).

The PSQ-PCR reactions were assembled with the EpMotion5070 liquid handling station (Eppendorf, Milan, Italy) in a final volume of $50 \mu \mathrm{l}$ containing $200 \mu \mathrm{mol} / \mathrm{l}$ dNTPs, $1 \times$ GeneAmp buffer $\left(1.5 \mathrm{mM} \mathrm{MgCl}_{2}\right), 1.25 \mathrm{U}$ of Immolase Hot Start polymerase (Bioline, Milan, Italy) and $0.3 \mu \mathrm{M}$ of the PCR primer pairs specific for the Fc $\gamma$ RIIIA $158 \mathrm{~V}>\mathrm{F}$ SNP. The Pyro Gold reagent kit PSQ 96MA was used for the sequencing reactions, according to the manufacturer instructions. The PSQ assay was performed using a PSQ96MA instrument (Qiagen, Milan, Italy) and the sequencing analysis was conducted with the PSQTM 96MA (version 2.02) software.

The Fc $\gamma$ RIIA $131 \mathrm{H}>\mathrm{R} S N P$ was analyzed by T-ARMS PCR [20] and by PCR amplification followed by SBT [7] in both forward and reverse directions using previously described methods.

Both Fc $\gamma$ RIIIA $158 \mathrm{~V}>\mathrm{F}$ and Fc $\gamma$ RIIA $131 \mathrm{H}>\mathrm{R}$ polymorphisms were independently re-tested in a different laboratory by T-ARMS PCR or SBT, as previously described, and results where fully concordant.

Table 1 Primers and conditions for the analysis of Fc $\gamma$ RIIIA gene polymorphism

\begin{tabular}{|c|c|c|c|}
\hline Name $^{a}$ & Primer sequence & Amplicon size (bp) & Sequence to analyze \\
\hline$F C \gamma R I I I A-F$ & AAGTCATTTGGGGTCAATTTC & $2416^{d}$ & \\
\hline Fc $\gamma R I I I A-R$ & CAGAATAGTTT $\underline{C A T C T C G T A T A T C}{ }^{b}$ & & \\
\hline FcrRIIIA-R-S & CAGGAATAAGGTGACGGTGG & 598 & \\
\hline Py-FcyRIIIA-F & Bio-AAAGCCACACTCAAAGACAGCC & $122^{\mathrm{e}}$ & MAAGCCCCCTGCAGAAGTAG ${ }^{f}$ \\
\hline$P y-F c \gamma R I I I A-R$ & ATTCCAGGGTGGCACATGTC & & \\
\hline Py-FcyRIIIA-S & ACACATTTTTACTCCCAA & & \\
\hline
\end{tabular}

a Genbank reference sequence: NG_009066.1; $F$ forward, $R$ reverse, Py pyrosequencing, $S$ sequence, Bio biotinylated

b In italic, underlined, is indicated the deliberate mismatch, from the reference sequence, introduced to improve primer stability

c To increase the specificity of the Fc $\gamma$ RIIIA amplification, the pyrosequencing primer was designed to include a cytosine (bold underlined) that is replaced by a thymidine in the Fc $\gamma$ RIIIB gene (genebank reference sequence. NG_032926.1)

d Cycling conditions: $30^{\prime \prime}$ at $94^{\circ} \mathrm{C}$ followed by 35 cycles at $94^{\circ} \mathrm{C}$ for $30^{\prime \prime}, 56^{\circ} \mathrm{C}$ for $30^{\prime \prime}, 68^{\circ} \mathrm{C}$ for $2^{\prime} 45^{\prime \prime}$ and a final cycle at $70^{\circ} \mathrm{C}$ for $10^{\prime}$

e Cycling conditions: $10^{\prime}$ at $95^{\circ} \mathrm{C}$ followed by 45 cycles at $95^{\circ} \mathrm{C}$ for $30^{\prime \prime}, 57^{\circ} \mathrm{C}$ for $30^{\prime \prime}, 72^{\circ} \mathrm{C}$ for $30^{\prime \prime}$ and a final cycle at $70^{\circ} \mathrm{C}$ for $10^{\prime}$

${ }^{f}$ The polymorphism, in bold, is reported according to the IUB (International Union of Biochemistry) nomenclature 


\section{Cell lines and culture conditions}

The BC cell lines SKBR3, BT474 and MCF-7 (American Type Culture Collection; ATCC, Rockville, MD, USA) were maintained in monolayer culture in RPMI 1640 medium supplemented with $10 \%$ heat-inactivated FBS, $5 \mathrm{mg} / \mathrm{ml}$ penicillin and $5 \mathrm{mg} / \mathrm{ml}$ streptomycin, $2 \mathrm{mM}$ L-glutamine, at $37{ }^{\circ} \mathrm{C}$ in a humidified $5 \% \mathrm{CO}_{2}$ atmosphere and subcultured every 3-7 days. The leukaemic cell line K562 (ATCC) was grown in complete RPMI 1640 culture medium. All reagents were purchased from Biochrom KG (Berlin, Germany).

\section{Analysis of trastuzumab reactivity by flow cytometry}

For HER-2 cell surface staining with trastuzumab antibody (Herceptin; Roche, Basel, Switzerland), titration assays were performed by indirect immunofluorescence using as targets SKBR3, BT474 and MCF-7 cell lines. In particular, $2 \times 10^{5}$ cells/sample were incubated with different concentrations $\left(2,0.2,0.02,2 \times 10^{-3}\right.$ and $2 \times 10^{-4} \mu \mathrm{g} / \mathrm{ml}$ ) of the $\mathrm{mAb}$ for $30 \mathrm{~min}$ at $4{ }^{\circ} \mathrm{C}$. After washing in FACS buffer, an Alexafluor 647-conjugated goat anti-human IgG secondary antibody (Molecular Probes, Inc. Eugene, OR, USA) was added and incubated for $30 \mathrm{~min}$ at $4{ }^{\circ} \mathrm{C}$. After 2 washes, the cells were analyzed by flow cytometry on a CyAn-ADP-Flow-Cytometer (Beckman-Coulter); 5000 cellular events were analyzed per sample. Data were analyzed using Summit version 4.3 Software (Beckman-Coulter).

Results were expressed as mean ratio of relative fluorescence intensity (MRFI), calculated as follows: mean fluorescence intensity (MFI) of HER-2 staining/MFI of secondary antibody staining.

\section{PBMC separation and antibody-dependent cellular cytotoxicity (ADCC) assay}

PBMCs were obtained after Ficoll-Hypaque density centrifugation of blood samples derived from $\mathrm{BC}$ patients before starting trastuzumab treatment. In particular, the NEO PBMCs included $4 \mathrm{~V} / \mathrm{V}$ carriers, $9 \mathrm{~V} / \mathrm{F}$ or $\mathrm{F} / \mathrm{F}$ carriers for the Fc $\gamma$ RIIIA $S N P$ and $3 \mathrm{H} / \mathrm{H}$ carriers, $10 \mathrm{H} / \mathrm{R}$ or R/R carriers for the Fc $\gamma$ RIIA SNP. The MTS PBMCs included $3 \mathrm{~V} / \mathrm{V}$ carriers, $6 \mathrm{~V} / \mathrm{F}$ or $\mathrm{F} / \mathrm{F}$ carriers for the Fc $\gamma$ RIIIA $S N P$ and $4 \mathrm{H} / \mathrm{H}$ carriers, $5 \mathrm{H} / \mathrm{R}$ or R/R carriers for the Fc $\gamma$ RIIA SNP.

Ex-vivo isolated PBMCs were used as effector cells in the ADCC assay in the presence of trastuzumab. As in preliminary experiments we found that ADCC triggering could be effective in a wide range of trastuzumab concentrations (from 2 to $2 \times 10^{-4} \mu \mathrm{g} / \mathrm{ml}$ ), we chose to perform all the cytolytic assays with trastuzumab at $2 \mu \mathrm{g} / \mathrm{ml}$ (concentration at which the differences in trastuzumab reactivity among target cell lines were more evident by flow cytometry). SKBR3, BT474 and MCF-7 target cells were labelled with sodium ${ }^{51} \mathrm{Chromate}\left({ }^{51} \mathrm{Cr}\right)$ and seeded in 96-V-bottomed microplates with effector cells $(\mathrm{E}) / \operatorname{target}(\mathrm{T})$ at different E:T ratios in $200 \mu \mathrm{l}$ of volume. Triplicate wells were set up for each E:T ratio and the percentage of lysis was calculated as previously described [21]. In details, the percent of specific cell lysis was calculated as [(experimental - spontaneous release)/ (maximum - spontaneous release) $\times 100$, in which spontaneous release refers to the ${ }^{51} \mathrm{Cr}$ release of target cells incubated for $4 \mathrm{~h}$ without effector cells. The maximum release is the ${ }^{51} \mathrm{Cr}$ release of each target cell in the presence of $1 \mathrm{~N} \mathrm{HCl}$. The maximum lysis was represented by the maximum - spontaneous release.

K562 cells were also used as HER-2 negative target cells. Basal cell lysis and ADCC were scored as present ( $\geq 5 \%$ of lysis) or absent ( $<5 \%$ of lysis). We estimated variability among the PBMC lytic activities by the coefficient of variation ( $\mathrm{CV} \%)$, calculated as the standard deviation of cell lysis values among all the PBMC samples tested divided by the mean and multiplied by 100 .

\section{Statistical analysis}

Deviation from the Hardy-Weinberg Equilibrium (HWE) was analyzed with the Pearson Chi square test by using the de Finetti program (http://ihg2.helmholtz-muenchen.de/cgi$\mathrm{bin} / \mathrm{hw} / \mathrm{hwa1}$.pl). A $P$ value $<0.05$ indicates a lack of HWE.

The comparison of genotype and allele frequencies between groups, as well as the association between genotype frequency, clinical-pathological parameters and response to trastuzumab were performed by the Pearson Chi square test or the Fisher's exact test, as appropriate. For the correlation test between response to trastuzumab and cytotoxicity (both basal and trastuzumab-mediated), the Bonferroni correction for three comparisons (indicated as $P^{c}$ ), that would require a $P$ value $<0.017$ to reject the null hypothesis, was applied. The comparison between basal cell lysis and trastuzumab-mediated lysis was performed using a paired Student's t test.

All statistical tests were two-sided and they were carried out using the SPSS package (version 19.0 for Windows). Statistical significance was accepted for any $P$ value $<0.05$.

\section{Results}

Frequencies of $F c \gamma$ RIIIA and FcyRIIA polymorphisms in HER-2 positive $B C$ patients and in control subjects In this study, we analysed Fc $\gamma$ RIIIA $158 \mathrm{~V}>\mathrm{F}$ and Fc $\gamma$ RIIA $131 \mathrm{H}>\mathrm{R}$ variants in 58 Italian subjects including 25 HER-2 positive BC patients. Out of these latter, 15 were in the neoadjuvant (NEO) setting and 10 in the metastatic (MTS) setting. Thirty-three healthy control women (CTR), matched for age, were also investigated. The main characteristics of patients are summarized in Table 2 . 
Table 2 Patient characteristics and response to trastuzumab

\begin{tabular}{llc}
\hline & NEO setting $\boldsymbol{n}$ (\%) & MTS setting $\boldsymbol{n}$ (\%) \\
\hline Number of patients & $15(100)$ & $10(100)$ \\
Median age, years (range) & $44.1(29-81)$ & $57.4(40-91)$ \\
$\leq 50$ & $8(53.3)$ & $4(40.0)$ \\
$>50$ & $7(46.7)$ & $6(60.0)$ \\
Menopausal status & & \\
Pre & $8(53.3)$ & $4(40.0)$ \\
Post & $7(46.7)$ & $6(60.0)$ \\
Hormonal status & & \\
Either ER+ or PgR+ & $8(53.3)$ & $6(60.0)$ \\
ER-/PgR- & $7(46.7)$ & $4(40.0)$ \\
Number of metastatic sites & & $5(50.0)$ \\
1 & - & $5(50.0)$ \\
$\geq 2$ & - & $3(30.0)$ \\
Metastatic sites & & $7(70.0)$ \\
Non visceral & - & \\
Visceral* & - & $3(30.0)$ \\
Response to trastuzumab & & $4(40.0)$ \\
Complete response & $12(80.0)$ & $3(30.0)$ \\
Partial response & $3(20.0)$ & - \\
Stable disease & - & \\
\hline
\end{tabular}

NEO neoadjuvant, $M T S$ metastatic, ER estrogen receptor, $P G R$ progesterone receptor (the cut-off value for ER and PGR positivity was $\geq 1 \%$ of tumor cells with nuclear staining)

* Visceral with or without non visceral metastatic sites
NEO and MTS patients showed similar frequencies of Fc $\gamma$ RIIIA genotypes $(P=0.763)$, as well as of alleles $(P=0.815$; data not shown), as previously reported [17].

Regarding the Fc $\gamma$ RIIA SNP, the NEO patients showed similar allele frequencies as compared to the MTS patients $(P=0.817$, data not shown) but a lower frequency of both homozygous genotypes and a higher frequency of the heterozygous genotype (20 vs $40 \% \mathrm{H} / \mathrm{H}, 26.7$ vs $40 \% \mathrm{R} / \mathrm{R}$ and 53.3 vs $20 \% \mathrm{H} / \mathrm{R}$ ), although this difference was not statistically significant (Table 3). The frequency of Fc $\gamma$ RIIIA and Fc $\gamma$ RIIA genotypes and alleles of $\mathrm{BC}$ patients did not significantly differ from those of healthy age-matched CTR when considered either separately (NEO vs CTR genotypes, $P=0.751$ and $P=0.836$, respectively; NEO vs CTR alleles, $P=0.716$ and $P=0.563$, respectively); MTS $v s$ CTR genotypes, $P=0.416$ and $P=0.202$, respectively; MTS vs CTR alleles, $P=0.961$ and $P=0.812$, respectively) or grouped together with CTR, as reported in Table 3.

Control women did not show significantly different Fc $\gamma$ RIIIA and Fc $\gamma$ RIIA genotype frequencies from those previously reported for the Italian healthy subjects [7, 22]. Moreover, no deviation from the Hardy-Weinberg equilibrium was observed for any of the polymorphisms in $\mathrm{BC}$ patients and CTR.

Table 3 Genotypic and allelic frequencies of Fc $\gamma$ RIIIA and Fc $\gamma$ RIIA polymorphisms in breast cancer patients and healthy controls

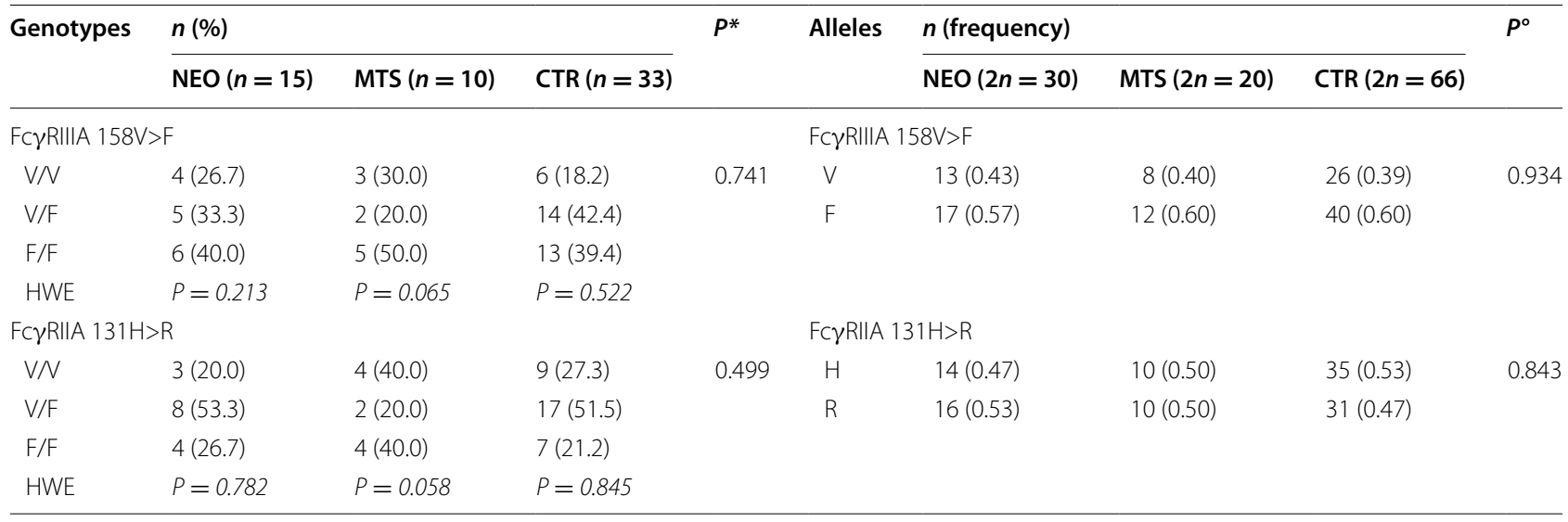

Genotyping of Fc $\gamma$ RIIIA $158 \mathrm{~V}>\mathrm{F}$ was performed by a newly developed PSQ method after pre-amplification of Fc $\gamma$ RIIIA gene. Genotyping of Fc $\gamma$ RIIA $131 \mathrm{H}>\mathrm{R}$ was performed by T-ARMS PCR and SBT. Conventionally, the $158 \mathrm{~V}>\mathrm{F}$ variant corresponds to the G>T SNP [i.e. guanine corresponding to valine (V) and thymine corresponding to phenylalanine $(\mathrm{F})$ ] and the $131 \mathrm{H}>\mathrm{R}$ SNP corresponds to the $\mathrm{A}>\mathrm{G}$ SNP [i.e. adenine corresponding to histidine $(\mathrm{H})$ and guanine corresponding to arginine $(\mathrm{R})]$

Comparison of Fc $\gamma$ R genotypic and allelic frequencies between patients and control subjects was estimated using the Pearson's $\chi^{2}$ test ( $P^{*}$ value) and the Fisher's test $\left(P^{\circ}\right.$ value), respectively. Statistical significance: $P<0.05$

NEO neoadjuvant, MTS metastatic, CTR controls, HWE Hardy-Weinberg equilibrium. HWE was tested by the Pearson's $\chi^{2}$ test $(P<0.05$ indicates lack of HWE) 


\section{Analysis of trastuzumab-mediated ADCC in BC patients}

We investigated whether PBMCs, ex vivo isolated from NEO and MTS BC patients before receiving trastuzumab, could be activated by the in vitro addition of trastuzumab to elicit ADCC upon interaction with HER-2 expressing BC cells. To this aim, PBMCs were used in a conventional cytolytic assay (at different $\mathrm{E}: \mathrm{T}$ ratios) against the three BC cell lines SKBR3, MCF-7 and BT474, expressing different levels of reactivity with trastuzumab, as shown by a titration assay using this mAb at different concentrations (from 2 to $2 \times 10^{-4} \mu \mathrm{g} / \mathrm{ml}$ ). In particular, at $0.02 \mu \mathrm{g} / \mathrm{ml}$ the flow cytometry profiles showed that SKBR3 expressed a high reactivity with trastuzumab, BT474 expressed an intermediate reactivity and MCF-7 expressed a low reactivity with trastuzumab (Fig. 1). This is consistent with previous reports showing SKBR3 as a high HER-2-expressing cell line and MCF-7 as a low or HER-2-negative cell line [23-25].
The cytolytic assays (ADCC) were performed at a constant concentration of $2 \mu \mathrm{g} / \mathrm{ml}$ of trastuzumab or medium alone (basal cytotoxicity) and results were estimated as mean percentage of specific cell lysis. This antibody concentration corresponds to one of the lowest concentration of trastuzumab found in patient serum during treatment (data not shown). Trastuzumab did not elicit ADCC of the HER-2 negative K562 cell line used as internal negative control (data not shown).

The results showed that PBMCs from the MTS patients killed BC cells more efficiently than PBMCs from the NEO patients, at all the E:T ratios both in the absence and in the presence of trastuzumab (Fig. 2). For instance, at 20:1 E:T ratio, the basal cytotoxicity observed for SKBR3, BT474 and MCF-7 was of 18, 8, $5 \%$ for MTS patients and of 10, 4, $7 \%$ for NEO patients, whereas in the presence of trastuzumab the percentage of lysis was 35, 24, $22 \%$ in the MTS cohort compared

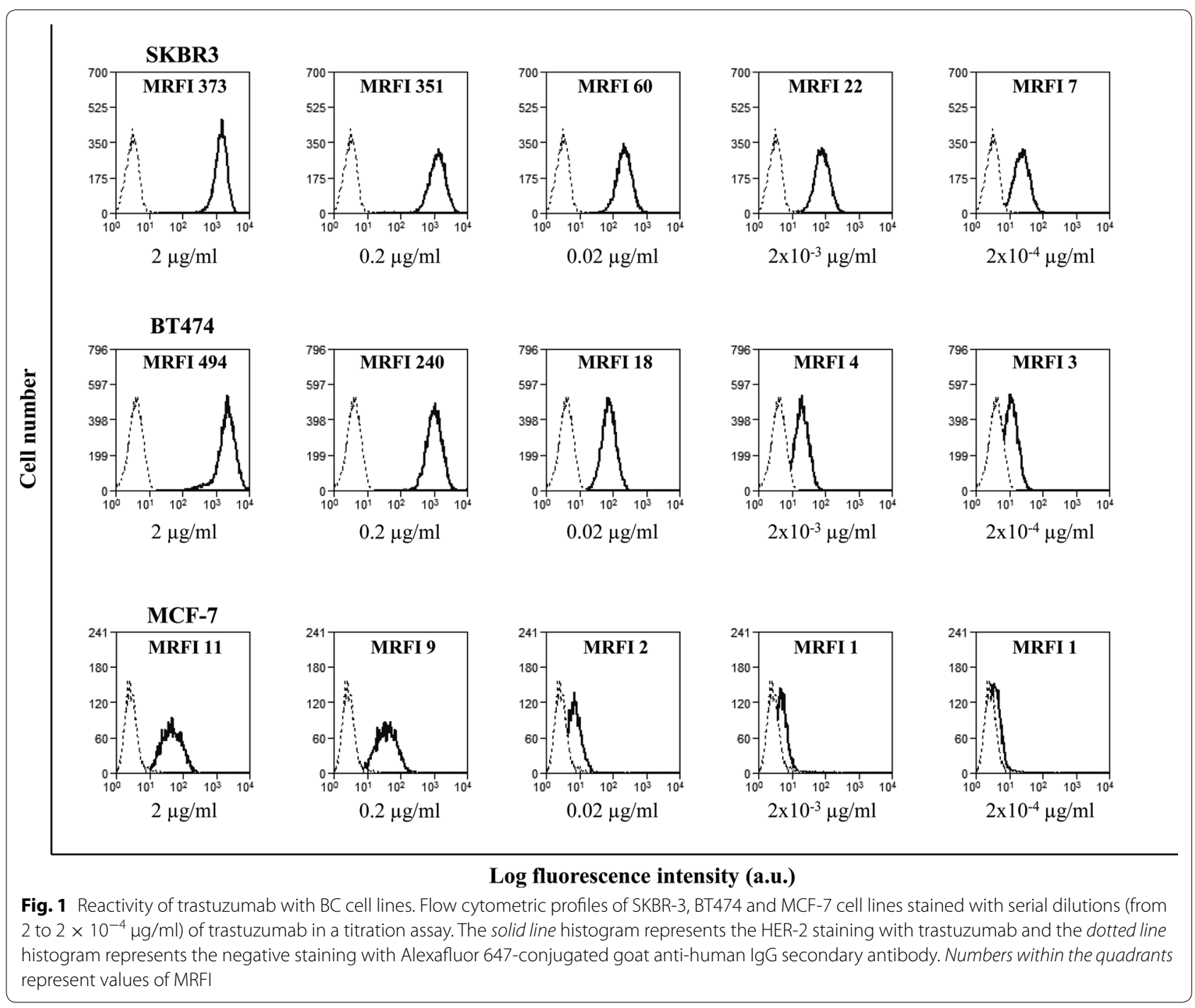




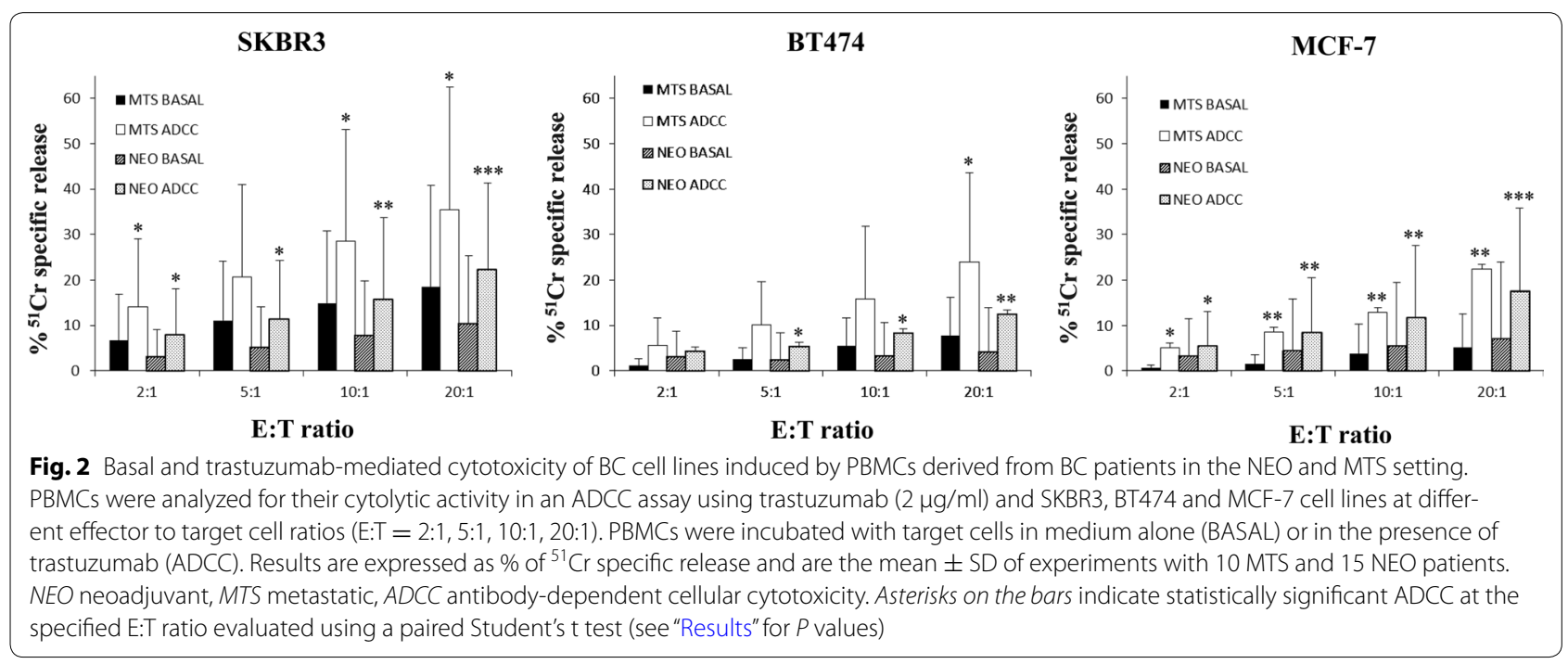

to $22,12,18 \%$ observed in NEO patients, respectively. ADCC was statistically significant at almost all the E:T ratios in both MTS and NEO patients ( $P$ values ranging from 0.017 to 0.021 with SKBR-3, from 0.002 to 0.012 with MCF-7, $P$ value $=0.038$ with BT474 for MTS; $P$ values at all $\mathrm{E}: \mathrm{T}$ ratios ranging from $<0.001$ to 0.010 with all cell lines for NEO). The ADCC degree of NEO and MTS patients mainly reflected the intensity of the cell line reactivity with trastuzumab: i.e. higher ADCC degree was observed with the SKBR3 cell line, followed by the BT474 and the MCF-7 cell lines. This finding was also confirmed in a cohort of healthy donors (not shown).

\section{Correlation of $F c \gamma$ RIIIA and $F c \gamma$ RIIA genotypes with the ADCC activity of PBMCs from BC patients in the NEO setting}

The results of the PBMC-mediated ADCC were then evaluated according to the Fc $\gamma$ RIIIA and Fc $\gamma$ RIIA gene polymorphisms. Considering the low number of patients within the two BC subgroups, we compared results obtained for the wild type Fc $\gamma$ RIIIA $158 \mathrm{~V} / \mathrm{V}$ and Fc $\gamma$ RIIA $131 \mathrm{H} / \mathrm{H}$ genotypes with those obtained for the mutated 158F (F/V together with $\mathrm{F} / \mathrm{F})$ and $131 \mathrm{R}(\mathrm{R} / \mathrm{H}$ together with $R / R$ ) carrier genotypes, respectively.

The cytolytic assays performed with the NEO patients showed that trastuzumab triggered PBMCs derived from the Fc $\gamma$ RIIIA $158 \mathrm{~V} / \mathrm{V}$ carriers (hereafter $158 \mathrm{~V} / \mathrm{V}$ carriers) to a statistically significant ADCC of SKBR3, BT474 and MCF-7 cell lines at high (20:1) E:T ratio $(P=0.022$, $P=0.042$ and $P=0.038$, respectively; Fig. $3 \mathrm{a}-\mathrm{c})$. Significant ADCC was also observed at 10:1 E:T ratio with SKBR3 and BT474 cell lines $(P=0.023$ and $P=0.048$, respectively).
PBMCs derived from the Fc $\gamma$ RIIIA 158F carriers (hereafter $158 \mathrm{~F}$ carriers) elicited a statistically significant ADCC of SKBR3 and BT474 cell lines at 20:1 E:T ratio $(\mathrm{P}=0.009$ and $\mathrm{P}=0.016$, respectively) and ADCC of MCF-7 also at lower E:T ratios $(\mathrm{P}=0.012, \mathrm{P}=0.039$ and $\mathrm{P}=0.019$ at 20:1, 10:1 and 5:1 E:T ratios, respectively) (Fig. $3 \mathrm{a}-\mathrm{c}$ ).

The NEO patients carrying the $158 \mathrm{~V} / \mathrm{V}$ variant showed a more pronounced ADCC against SKBR3 and BT474 target cell lines at all the E:T ratios, as compared to the $158 \mathrm{~F}$ carriers, although this difference was not statistically significant (Fig. 3a, b).

The enhancement of basal lysis induced by the $158 \mathrm{~V} / \mathrm{V}$ carriers was independent from the reduction of HER-2 expression on target cells, whereas the one induced by the 158 F carriers was slightly decreasing with the reduction of HER-2 expression (Additional file 1).

Concerning the Fc $\gamma$ RIIA polymorphism, PBMCs derived from the Fc $\gamma$ RIIA $131 \mathrm{H} / \mathrm{H}$ carrier (hereafter $131 \mathrm{H} / \mathrm{H}$ carriers) NEO patients elicited significant ADCC of SKBR3, BT474 and MCF-7 cell lines at an E:T ratio of 20:1 $(P=0.010, P=0.029$ and $P=0.049$, respectively; Fig. $3 d-f)$, whereas for PBMCs derived from the $131 \mathrm{R}$ carriers (hereafter 131R carriers), significant ADCC of the three cell lines was observed from 20:1 to 5:1 E:T ratios $(P$ values ranging from $\mathrm{P}=0.007$ to $\mathrm{P}=0.047$; Fig. 3d-f).

The $131 \mathrm{H} / \mathrm{H}$ carriers elicited higher ADCC degrees as compared to the $131 \mathrm{R}$ carriers against all three cell lines, but this difference did not reach statistical significance.

The enhancement of basal lysis induced by the $131 \mathrm{H} / \mathrm{H}$ carriers was independent from HER-2 expression on target cells, whereas the one induced by the $131 \mathrm{R}$ carriers was decreasing with the reduction of HER-2 expression 


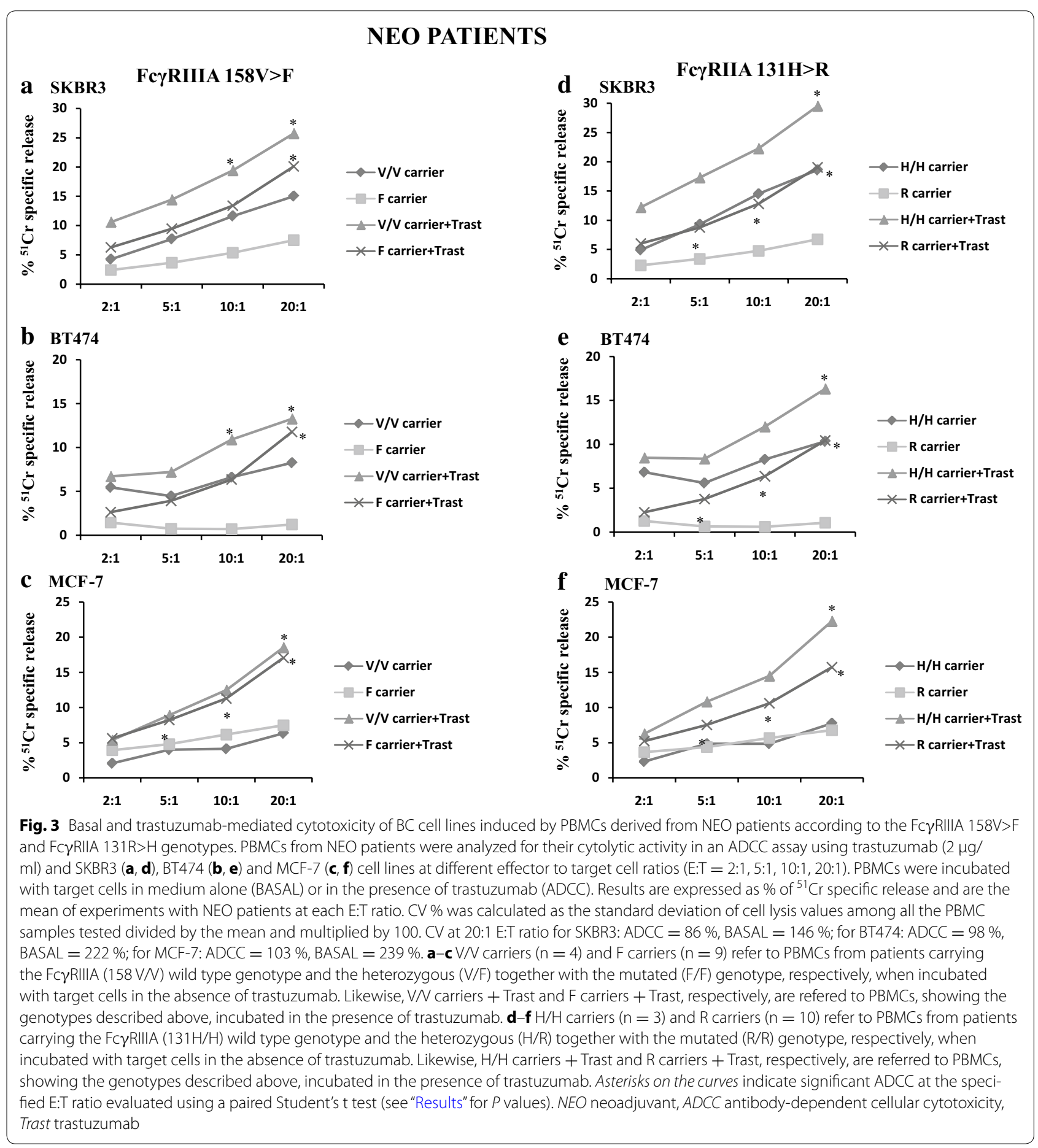

(Additional file 1). Examples of ADCC and basal lysis for each NEO patient are provided against the MCF-7 cell line in Additional file 2.

All these findings demonstrate that, in the NEO patients, both the Fc $\gamma$ RIIIA 158F and Fc $\gamma$ RIIA 131R carrier genotypes can efficiently induce ADCC also at low E:T ratios and that different HER-2 expression levels on tumor target cells can affect the intensity of ADCC triggered by the Fc $\gamma$ RIIIA 158F and 131R carriers. 


\section{Correlation of $F c y R$ IIIA and $F c y R$ RIIA genotypes with the ADCC activity of PBMCs from BC patients in the MTS setting}

The cytolytic assays performed with the MTS patients show that trastuzumab triggered PBMCs derived from the Fc $\gamma$ RIIIA158F carriers to a significant ADCC of SKBR3 and MCF-7 target cells at any of the E:T ratios tested ( $P$ values ranging from 0.015 to 0.032 and from 0.009 to 0.013 , respectively; Fig. 4a, c). In the case of BT474, a trend toward a statistically significant ADCC was observed only at the 20:1 E:T ratio $(\mathrm{P}=0.083$; Fig. 4b) due to the high variability of ADCC levels observed among patients. In contrast, PBMCs from the $158 \mathrm{~V} / \mathrm{V}$ carriers did not elicit significant ADCC at any E:T ratio with the cell lines tested.

The 158F carrier PBMCs showed a more pronounced ADCC as compared to the $158 \mathrm{~V} / \mathrm{V}$ carriers, at all the E:T ratios, with SKBR3 and BT474 target cells, but not with MCF-7 target cells (Fig. 4; Additional file 1).

The enhancement of basal lysis induced by the $158 \mathrm{~F}$ carriers, in the presence of trastuzumab, decreased with the reduction of HER-2 expression on target cells, whereas the one induced by the $158 \mathrm{~V} / \mathrm{V}$ carriers increased with the reduction of HER-2 surface expression, at any of the E:T ratios (Additional file 1).

Concerning the Fc $\gamma$ RIIA polymorphism, PBMCs derived from the $131 \mathrm{H} / \mathrm{H}$ carrier or $131 \mathrm{R}$ carrier MTS patients triggered statistically significant $\mathrm{ADCC}$ against $\mathrm{BT} 474$ or MCF-7 cell lines at 20:1 E:T ratio $(P=0.028$ and $P=0.034$, respectively) (Fig. 4e, f). The $131 \mathrm{H} / \mathrm{H}$ carriers induced a more pronounced ADCC as compared to the 131R carriers against SKBR3 and MCF-7 (Fig. 4d, f), although this difference did not reach statistically significance.

The enhancement of basal lysis induced by both the $131 \mathrm{H} / \mathrm{H}$ and $131 \mathrm{R}$ carriers, in the presence of trastuzumab, was independent from the reduction of HER-2 expression on target cells, at any of the E:T ratios (Additional file 1). Examples of ADCC and basal lysis for each MTS patient are provided against the MCF-7 cell line in Additional file 3.

Taken together, these findings demonstrate that the Fc $\gamma$ RIIIA158F carrier genotype can behave as a favourable genotype for promoting ADCC. In addition, different HER-2 expression levels on tumor target cells can affect the intensity of ADCC triggered by the Fc $\gamma$ RIIIA $158 \mathrm{~V} / \mathrm{V}$ and $158 \mathrm{~F}$ carriers. These findings were confirmed in a cohort of healthy donors (Additional file 4).

\section{Correlation of basal cytotoxicity and ADCC with prognostic factors and response to trastuzumab}

Taking into account that cell cytotoxicity was scored as present ( $\geq 5 \%$ of lysis) or absent ( $<5 \%$ of lysis), we found that, in the NEO patients, the pathological complete response (pCR) to trastuzumab significantly correlated with an increased frequency of patients showing ADCC (Table 4). Indeed, the number of patients with present cytotoxicity in the absence of trastuzumab (BASAL) significantly increased after addition of trastuzumab (from 18.2 to $90.9 \%$ with MCF-7 cell line; $P=0.002$; Bonferroni corrected $P^{c}=0.006$ ). A noticeable increase was also observed with BT747 (from 11.1 to $66.7 \%$ ) and SKBR3 (from 36.4 to $81.8 \%$ ), although it was not statistically significant.

When basal cytotoxicity and ADCC were correlated to the partial response (pPR) no statistically significant results were observed. This analysis was limited by the extremely low number of patients $(\mathrm{n}=2$ or 3 depending on the cell line used as target; Table 4). Also in the MTS subgroup, the frequency of patients with present cytotoxicity in the CR subgroup increased, upon addition of trastuzumab, when the MCF-7 cell line was used as target (data not shown).

These results suggest that ADCC can play a role in the response to trastuzumab and that this role can be better detectable when using, as target cells, a $\mathrm{BC}$ cell line showing low trastuzumab reactivity, such as MCF-7.

We did not find any significant correlation between Fc $\gamma$ RIIIA and Fc $\gamma$ RIIA gene polymorphisms, basal cell lysis and ADCC with patient age, life status (alive or dead) and prognostic factors including menopausal status, hormonal receptor status, number and sites of metastases, that were found to display significant association with Fc $\gamma$ RIIIA/IIA polymorphisms in previous studies [18]. Finally, we did not observe any significant correlations between Fc $\gamma$ RIIIA or Fc $\gamma$ RIIA SNPs and patient response to trastuzumab.

\section{Discussion}

Trastuzumab is a human mAb that specifically binds the extracellular domain of HER-2 receptor expressed by $\mathrm{BC}$ cells. Trastuzumab is currently used as a single agent [26] and in combination with chemotherapy [27-29] for the treatment of women with either early [30] or advanced HER-2 overexpressing BC [27, 28]. The principal mechanisms of action of trastuzumab include direct growth inhibition leading to apoptosis of tumor cells, complement-dependent cytotoxicity and ADCC by NK cells, monocytes and granulocytes [31].

It has been previously shown that functional $\mathrm{Fc} \gamma \mathrm{R}$ SNPs can regulate the trastuzumab-mediated ADCC and predict the clinical outcome of $\mathrm{BC}$ patients treated with trastuzumab-based therapy [7, 17, 32].

In this study, we investigated in vitro the ADCC elicited by PBMCs from NEO and MTS BC patients and correlated its extent with Fc $\gamma$ RIIIA 158V $>$ F and Fc $\gamma$ RIIA $131 \mathrm{H}>\mathrm{R}$ genotypes and response to trastuzumab. 


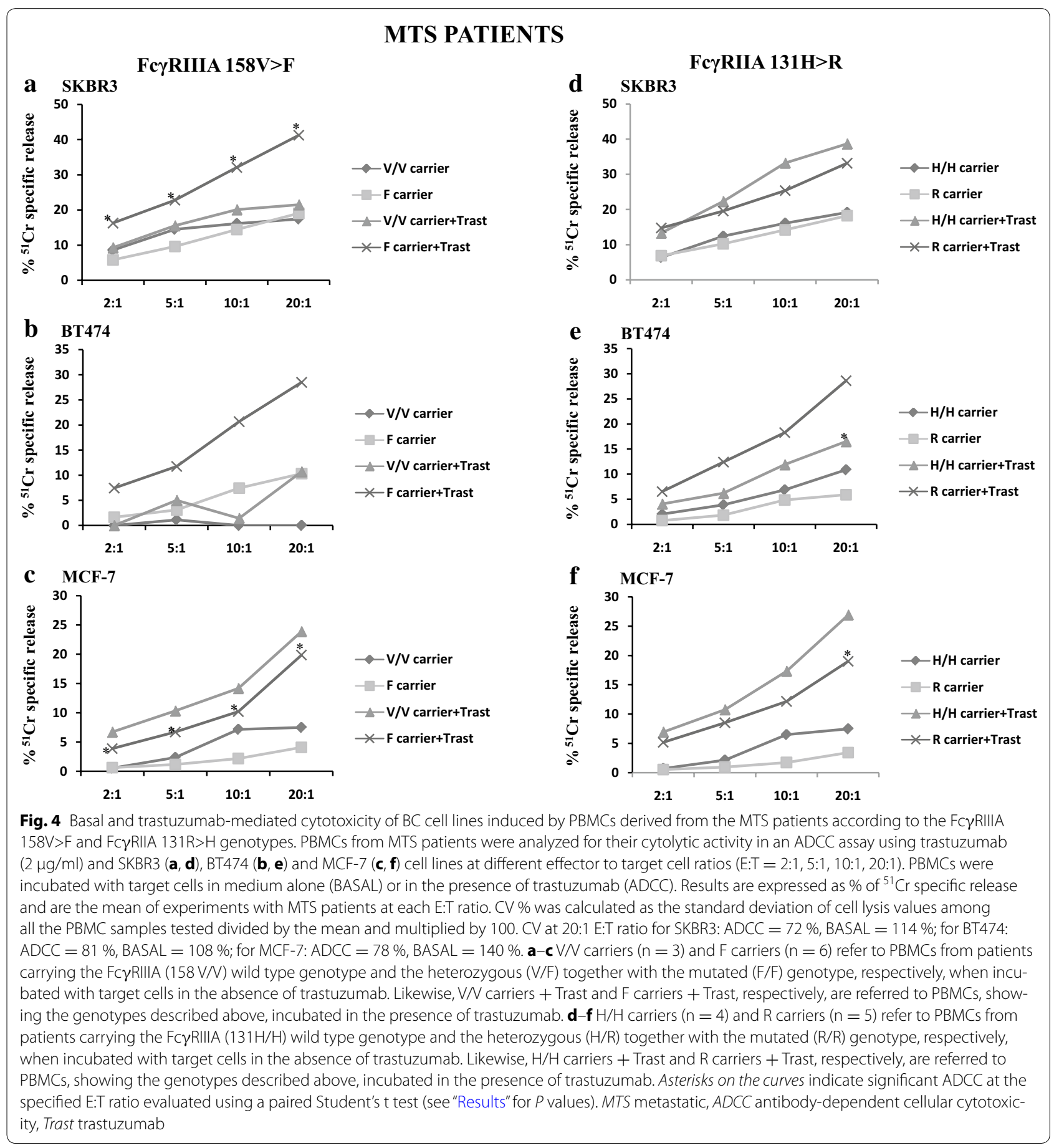

We found that the Fc $\gamma$ RIIIA $158 \mathrm{~F}$ and/or the Fc $\gamma$ RIIA $131 \mathrm{R}$ genotypes, that are commonly reported as unfavourable genotypes not only in $\mathrm{BC}[7,32]$ but also in other tumours $[10,11]$, may actually behave as favourable genotypes. Indeed, the $158 \mathrm{~F}$ and $131 \mathrm{R}$ genotypes were able to elicit a stronger ADCC, as compared to the $158 \mathrm{~V} / \mathrm{V}$ and $131 \mathrm{H} / \mathrm{H}$ genotypes, which remained significant also at low E:T ratios. In addition, in some instances, only the $158 \mathrm{~F}$ and $131 \mathrm{R}$ genotypes showed significant ADCC. The MCF-7 cell line has previously been found weakly- or not-expressing HER-2 [24, 25, 33, 34] so that it has been used as a negative control for trastuzumab-mediated ADCC [34]. In our experimental system, MCF-7 displayed low, but detectable, reactivity with 
Table 4 Correlation of basal cytotoxicity and ADCC with response to trastuzumab of neoadjuvant breast cancer patients

\begin{tabular}{|c|c|c|c|c|c|c|c|}
\hline \multirow[t]{3}{*}{ NEO patients } & \multirow{2}{*}{\multicolumn{2}{|c|}{$\frac{\mathrm{pPR}(\mathrm{n}=3)}{\text { Cytotoxicity }}$}} & \multirow[t]{3}{*}{$P$} & \multirow{2}{*}{\multicolumn{2}{|c|}{$\frac{\mathrm{pCR}(\mathrm{n}=12)}{\text { Cytotoxicity }}$}} & \multirow[t]{3}{*}{$P$} & \multirow[t]{3}{*}{$P^{c}$} \\
\hline & & & & & & & \\
\hline & $B A S A L$ & $A D C C$ & & $B A S A L$ & $A D C C$ & & \\
\hline SKBR3 & $n=3$ & $n=3$ & & $n=11$ & $n=11$ & & \\
\hline Present & $1(33.3)$ & $3(100.0)$ & 0.400 & $4(36.4)$ & $9(81.8)$ & 0.080 & 0.240 \\
\hline Absent & $2(66.7)$ & $0(-)$ & & $7(63.6)$ & $2(18.2)$ & & \\
\hline BT474 & $n=2$ & $n=2$ & & $n=9$ & $n=9$ & & \\
\hline Present & $0(-)$ & $1(50.0)$ & 0.400 & $1(11.1)$ & $6(66.7)$ & 0.050 & 0.147 \\
\hline Absent & $2(100.0)$ & $1(50.0)$ & & $8(88.9)$ & $3(33.3)$ & & \\
\hline MCF-7 & $n=2$ & $n=2$ & & $n=11$ & $n=11$ & & \\
\hline Present & $0(-)$ & $2(100.0)$ & 0.333 & $2(18.2)$ & $10(90.9)$ & 0.002 & 0.006 \\
\hline Absent & $2(100.0)$ & $0(-)$ & & $9(81.8)$ & $1(9.1)$ & & \\
\hline
\end{tabular}

PBMCs were analyzed for their cytolytic activity in an ADCC assay using trastuzumab ( $2 \mu \mathrm{g} / \mathrm{ml})$ and SKBR3, BT474 and MCF-7 cell lines at $20: 1$ effector to target cell ratio. PBMCs were incubated with target cells in medium alone (BASAL) or in the presence of trastuzumab (ADCC). Results are expressed as number and percentages (in brackets) of patients showing basal or trastuzumab-mediated cytotoxicity (cut off: $>5 \%$ )

Comparison of BASAL cytotoxicity and ADCC was estimated using the Fisher's test ( $P$ value) (significance level $<0.05)$ and further adjusted with Bonferroni correction for multiple comparisons ( $P^{\complement}$ value) in the indicated patients

NEO neoadjuvant, $A D C C$ antibody-dependent cellular cytotoxicity, $p P R$ pathological partial response, $p C R$ pathological complete response

trastuzumab by flow cytometry, as compared to SKBR3 and BT474 cell lines that showed high reactivity. Therefore, our ADCC results with MCF-7 cell line may have implications in trastuzumab-based therapy because they suggest that also tumor cells which are not HER-2-amplified and display low levels of HER-2 expression can be efficiently targeted with trastuzumab.

In the NEO patients, the Fc $\gamma$ RIIIA $158 \mathrm{~V} / \mathrm{V}$ genotype correlated with a statistically significant ADCC in all cell lines tested, at high E:T ratios, whereas this correlation was not observed in the MTS patients at any E:T ratio. The Fc $\gamma$ RIIA131H/H genotype correlated with a statistically significant ADCC at high E:T ratios with two or three cell lines depending on the setting, NEO or MTS, analyzed.

Although different effector cell types within PBMCs can engage trastuzumab, we here chose to evaluate the overall lytic activity of PBMCs isolated before starting trastuzumab therapy in order to mimic the ADCC condition that may occur in vivo. For this reason, we evaluated the Fc $\gamma$ RIIIA and Fc $\gamma$ RIIA gene polymorphisms that are respectively involved in the activation of the NK cell population and other accessory cells of the immune system. We found a broad interindividual variability of ADCC levels among patients which might be related to the Fc $\gamma R$ genotypes, as well as to the proportion and/or lytic efficiency of effector cells present in the PBMCs samples.

The ADCC variability was indicated by the high $\mathrm{CV}$ values that we observed among all the PBMC samples tested (CVs ranging from 72 to $103 \%$, depending on the $\mathrm{BC}$ setting and target cell line). Remarkably, we noticed that the variability was more pronounced in the spontaneous (basal) cytotoxicity (CVs ranging from 108 to $239 \%$ ), as compared to ADCC, condition that was also observed among healthy individuals (Additional file 4 ). To explain the lower $\mathrm{CV}$ values in trastuzumab-mediated cell lysis, it is conceivable that the addition of trastuzumab to the cytolytic assay provides an optimal stimulus to trigger the activation of cytolytic effector cells. Indeed, the Fc $\gamma$ RIIIA engagement with trastuzumab resulted in a homogeneous triggering of Fc $\gamma$ RIIIA + PBMCs abrogating the individual specific feature of spontaneous lysis of each donor and pointing out their maximal cytolysis. Indeed, only using trastuzumab we could find a biologically significant degree of target cell lysis.

Altogether, the MTS patients showed higher levels of ADCC against all BC cell lines used as targets, as compared to the NEO patients, thus confirming that ADCC can be efficient also in the advanced stage of $B C$, as reported in previous studies [7, 35]. A possible explanation for the higher ADCC in MTS patients may be the different immunologic context under which immune cells become activated in the two patient settings. In particular, the immune response elicited by $\mathrm{BC}$ in the NEO patients might be confined to the tumour microenvironment whereas that elicited in the MTS patients might be systemic resulting from a generalized and more potent immune cell stimulation due to the spread of $\mathrm{BC}$ to other parts of the body. Indeed, we found that the ADCC observed in MTS patients was similar, in intensity and variability, to that observed in healthy donors suggesting that MTS patients are in a different activation state as 
compared to NEO patients. Thus, the different efficacy of MTS and NEO cytolytic activity may be due to intrinsic biological characteristics of the immune cells (activation state, lytic efficiency, different cell number) rather than to the effects of clinical-pathological parameters. In both BC subgroups, the entity of ADCC reflected the HER-2 expression levels as the highest absolute values were observed with the SKBR3 cell line.

In NEO and MTS subgroups the enhancement of basal lysis induced by the Fc $\gamma$ RIIIA158F carriers was dependent on HER-2 expression, whereas the one induced by the $158 \mathrm{~V} / \mathrm{V}$ carriers was dependent on HER-2 expression only in the MTS subgroup. Concerning the Fc $\gamma$ RIIA, the enhancement of basal lysis induced by the $\mathrm{H} / \mathrm{H}$ carriers was independent from HER-2 expression in both MTS and NEO subgroups and the one induced by the 131R carrier was dependent on HER-2 expression in NEO, but not in MTS patients.

In summary, these data demonstrate a different behaviour, in respect to the Fc $\gamma \mathrm{R}$ genotypes and ADCC extent, of $\mathrm{BC}$ cell lines expressing different HER-2 levels. These levels might be representative of the tumour and intratumoral heterogeneity of HER-2 expression that has recently been reported in a proportion of breast cancers (36). This heterogeneity is clinically relevant for its association with the response to HER-2-targeted therapy.

To date, there are still conflicting reports in the literature concerning the role of $\mathrm{Fc} \gamma \mathrm{R}$ polymorphisms in the clinical outcome of trastuzumab-treated $\mathrm{BC}$ patients. Even the largest retrospective analysis performed by Hurwitz et al. in the adjuvant and metastatic settings does not seem to completely exclude a contribution of $\mathrm{Fc} \gamma \mathrm{R}$ polymorphisms and ADCC/Fc $\gamma \mathrm{R}$ engagement to the outcome of trastuzumab-treated patients [18]. Thus, the conflicting results may derive from different factors including ethnical differences in the SNP frequency, genotyping problems due to the high homology between Fc $\gamma \mathrm{R}$ members, differences in the modalities of therapeutic use of trastuzumab (i.e. NEO, MTS or adjuvant setting) or in the chemotherapy regimen.

In addition, only few reports analyzed the association of Fc $\gamma \mathrm{R}$ polymorphisms with ADCC intensity and with clinical outcome [7, 8]; other reports analyzed only the association of $\mathrm{Fc} \gamma \mathrm{R}$ polymorphisms with clinical response without taking into account the ADCC $[17,18$, 32 ], or the association between ADCC and response to trastuzumab without considering the Fc $\gamma \mathrm{R}$ gene polymorphisms [34, 35]. Although performed in a quite small number of patients, our study correlates Fc $\gamma \mathrm{R}$ gene polymorphisms to the ADCC extent in combination with the HER-2 expression levels on tumor target cells. Similarly, this study also correlates $\mathrm{Fc} \gamma \mathrm{R}$ polymorphisms to the basal lysis extent. Indeed, in both NEO and MTS patients the $158 \mathrm{~V} / \mathrm{V}$ carriers showed, in some instances, a more pronounced lysis as compared to that of the $158 \mathrm{~F}$ carriers, although in MTS patients with BT474 cell line we found that $158 \mathrm{~F}$ carrier showed a more efficient basal lysis than $158 \mathrm{~V} / \mathrm{V}$. However, this difference was not statistically significant and may depend on intrinsic features of each patient.

Our results demonstrate a statistically significant correlation of the ADCC degree with the complete response of NEO patients to trastuzumab. In particular, the frequency of patients with positive ADCC was significantly increased using the MCF-7 cell line as target, as compared to patients without ADCC; this suggests that also small variations in the percent of cell lysis observed in vitro might contribute to the induction of a complete response in vivo.

It is of note that the increase of patients showing cytotoxicity was observed with the MCF-7 cell line suggesting that the use of low-HER-2-expressing cells might be useful for testing of ADCC.

Even if further investigations in larger cohort studies are required to confirm our findings, these results provide additional information for a better understanding of the role of $\mathrm{Fc} \gamma \mathrm{R}$ gene polymorphisms/ADCC in trastuzumab-treated $\mathrm{BC}$; this study might improve the testing of patient ADCC in order to identify subgroups of patients who might benefit from trastuzumab treatment.

\section{Conclusions}

In our experimental system, we could detect that unfavourable Fc $\gamma$ RIIIA158F carrier or Fc $\gamma$ RIIA131R carrier genotypes may actually behave as favourable genotypes.

Despite the limitation due to the small number of patients enrolled, our findings would suggest that in the in vitro assays for the ADCC activity of patients eligible for trastuzumab therapy it might be useful to include a panel of $B C$ cell lines showing different HER-2 expression levels, as they may reflect the in vivo HER-2 heterogeneity in different tumor areas [36].

\section{Additional files}

Additional file 1: Table S1. Enhancement of basal lysis of different BC cell lines induced in the presence of trastuzumab.

Additional file 2: Figure S1 Basal and trastuzumab-mediated cytotoxicity of MCF-7 cell line induced by PBMCs derived from the NEO individual patients.

Additional file 3: Figure S2. Basal and trastuzumab-mediated cytotoxicity of MCF-7 cell line induced by PBMCs derived from the MTS individual patients.

Additional file 4: Figure S3. Basal and trastuzumab-mediated cytotoxicity of BC cell lines induced by PBMCs derived from healthy donors. 


\section{Abbreviations}

ADCC: antibody-dependent cellular cytotoxicity; BC: breast cancer; Fc $\gamma$ R: Fc $\gamma$ Receptor; E:T ratio: effector:target ratio; HWE: Hardy-Weinberg Equilibrium; $\mathrm{mAb}$ : monoclonal antibody; MRFI: mean ratio of relative fluorescence intensity; MTS: metastatic; NEO: neoadjuvant; PBMCs: peripheral blood mononuclear cells; pCR: pathological complete response; pPR: pathological partial response; PSQ: pyrosequencing; SBT: sequence-based typing; SNPs: single nucleotide polymorphisms; T-ARMS PCR: tetra-primer amplification refractory mutation system PCR; Trast: trastuzumab.

\section{Authors' contributions}

MPP and AP conceived the study, participated in its design and coordination and drafted the manuscript. AP carried out ADCC experiments in healthy donors. SB carried out ADCC assays. BB and MR developed, carried out and interpreted the PSQ genotyping assay. AM and RC extracted genomic DNA. PP, $S L, A M$ and RC carried out and interpreted T-ARMS and SBT genotypings. BC and GLL coordinated blood collections and collected data from the medical records. BD performed the statistical analyses. SS performed HER-2 IHC and FISH analyses. AL and LD selected and coordinated breast cancer patients. FP and AD selected patients and collected clinical data. All authors read and approved the final manuscript.

\section{Author details}

${ }^{1}$ Unit of Molecular Oncology and Angiogenesis, IRCCS AOU San Martino-IST, Genoa, Italy. ${ }^{2}$ Unit of Tumor Epigenetics, IRCCS AOU San Martino-IST, Genoa, Italy. ${ }^{3}$ Development of Innovative Therapies Unit, IRCCS AOU San Martino-IST, Genoa, Italy. ${ }^{4}$ Clinical Epidemiology Unit, IRCCS AOU San Martino-IST, Genoa, Italy. ${ }^{5}$ Medical Oncology Unit, Sacro Cuore Don Calabria Hospital, Negrar, Verona, Italy. ${ }^{6}$ Cellular Biology Unit, IRCCS AOU San Martino-IST, Genoa, Italy. ${ }^{7}$ Laboratory of Molecular Diagnostics, IRCCS AOU San Martino-IST, Genoa, Italy. ${ }^{8}$ Unit of Pathology, IRCCS AOU San Martino-IST, Genoa, Italy. ${ }^{9}$ Unit of Medical Oncology 2, IRCCS AOU San Martino-IST, Genoa, Italy.

\section{Acknowledgements}

This work was supported by grants awarded from the Italian Ministry of Health (5 × 1000 funds 2011 and RF-2010-2311299) and AIRC grant to AP (IG15483). $\mathrm{BB}$ is the recipient of the "Young Investigators" grant GR-2008-1143408 from the Italian Ministry of Health. The authors thank Antonino Musolino for providing primer sequences and PCR conditions for Fc $\gamma$ RIIA genotyping, Mrs Giuseppina lacono and Dr. Ornella Vannozzi for assistance in blood sample collection, the blood donors and staff of both the Transfusion Centers of Galliera Hospital and the IRCCS AOU San Martino-IST, Genoa (Italy), for kindly providing buffy coats and Dr. Vincenzo Fontana for helpful suggestions on statistical analyses.

\section{Competing interests}

The authors declare that they have no competing interests.

Received: 15 January 2015 Accepted: 24 September 2015

Published online: 08 October 2015

\section{References}

1. Ravetch JV, Kinet JP. Fc receptors. Annu Rev Immunol. 1991;9:457-92.

2. Ivan E, Colovai A. Human Fc receptors: critical targets in the treatment of autoimmune diseases and transplant rejections. Hum Immunol. 2006;67:479-91.

3. Clynes RA, Towers TL, Presta LG, Ravetch JV. Inhibitory Fc receptors modulate in vivo cytotoxicity against tumor targets. Nat Med. 2000;6:443-6.

4. Carson WE, Parihar R, Lindemann MJ, Personeni N, Dierksheide J, Meropol NJ, Baselga J, Caligiuri MA. Interleukin-2 enhances the natural killer cell response to Herceptin-coated Her2/neu-positive breast cancer cells. Eur J Immunol. 2001;31:3016-25.

5. Parihar R, Dierksheide J, Hu Y, Carson WE. IL-12 enhances the natural killer cell cytokine response to Ab-coated tumor cells. J Clin Invest. 2002;110:983-92.

6. Gennari R, Menard S, Fagnoni F, Ponchio L, Scelsi M, Tagliabue E, Castiglioni F, Villani L, Magalotti C, Gibelli N, Oliviero B, Ballardini B, Da Prada G, Zambelli A, Costa A. Pilot study of the mechanism of action of preoperative trastuzumab in patients with primary operable breast tumors overexpressing HER2. Clin Cancer Res. 2004;10:5650-5.

7. Musolino A, Naldi N, Bortesi B, Pezzuolo D, Capelletti M, Missale G, Laccabue D, Zerbini A, Camisa R, Bisagni G, Neri TM, Ardizzoni A. Immunoglobulin $\mathrm{G}$ fragment $C$ receptor polymorphisms and clinical efficacy of trastuzumab-based therapy in patients with HER-2/neu-positive metastatic breast cancer. J Clin Oncol. 2008;26:1789-96.

8. Varchetta S, Gibelli N, Oliviero B, Nardini E, Gennari R, Gatti G, Silva LS, Villani L, Tagliabue E, Ménard S, Costa A, Fagnoni FF. Elements related to heterogeneity of antibody-dependent cell cytotoxicity in patients under trastuzumab therapy for primary operable breast cancer overexpressing Her2. Cancer Res. 2007;67:11991-11999.

9. Mellor JD, Brown MP, Irving HR, Zalcberg JR, Dobrovic A. A critical review of the role of Fc gamma receptor polymorphisms in the response to monoclonal antibodies in cancer. J Hematol Oncol. 2013;6:1-10.

10. Weng WK, Levy R. Two immunoglobulin $G$ fragment $C$ receptor polymorphisms independently predict response to rituximab in patients with follicular lymphoma. J Clin Oncol. 2003;21:3940-7.

11. Bibeau F, Lopez-Crapez E, Di Fiore F, Thezenas S, Ychou M, Blanchard F, Lamy A, Penault-Llorca F, Frebourg T, Michel P, Sabourin JC, BoissièreMichot F. Impact of Fc $\gamma$ RIlla-Fc $\gamma$ RIIIla polymorphisms and KRAS mutations on the clinical outcome of patients with metastatic colorectal cancer treated with cetuximab plus irinotecan. J Clin Oncol. 2009;27:1122-9.

12. Harries M, Smith I. The development and clinical use of trastuzumab (Herceptin). Endocr Relat Cancer. 2002;9:75-85.

13. Mukohara T. Mechanisms of resistance to anti-human epidermal growth factor receptor 2 agents in breast cancer. Cancer Sci. 2011;102:1-8.

14. Koene HR, Kleijer M, Algra J, Roos D, von dem Borne AE, de Haas M. FC gammaRIIla-158V/F polymorphism influences the binding of IgG by natural killer cell Fc $\gamma$ RIIIla, independently of the Fc $\gamma$ RIIla-48L/R/H phenotype. Blood. 1997;90:1109-14.

15. Shields RL, Namenuk AK, Hong K, Meng YG, Rae J, Briggs J, Xie D, Lai J, Stadlen A, Li B, Fox JA, Presta LG. High resolution mapping of the binding site on human IgG1 for Fc gamma RI, Fc gamma RII, Fc $\gamma$ RIII, and FCRn and design of IgG1 variants with improved binding to the FC $\gamma$ R. J Biol Chem. 2001;276:6591-604.

16. Warmerdam PA, van de Winkel JG, Vlug A, Westerdaal NA, Capel PJ A single amino acid in the second Ig-like domain of the human FC gamma receptor II is critical for human IgG2 binding. J Immunol. 1991;147:1338-43.

17. Tamura K, Shimizu C, Hojo T, Akashi-Tanaka S, Kinoshita T, Yonemori K, Kouno T, Katsumata N, Ando M, Aogi K, Koizumi F, Nishio K, Fujiwara Y. Fc $\gamma R 2 A$ and $3 A$ polymorphisms predict clinical outcome of trastuzumab in both neoadjuvant and metastatic settings in patients with HER2positive breast cancer. Ann Oncol. 2011;22:1302-7.

18. Hurvitz SA, Betting DJ, Stern HM, Quinaux E, Stinson J, Seshagiri S, Zhao Y, Buyse M, Mackey J, Driga A, Damaraju S, Sliwkowski MX, Robert NJ, Valero V, Crown J, Falkson C, Brufsky A, Pienkowski T, Eiermann W, Martin M, Bee $\checkmark$, Marathe O, Slamon DJ, Timmerman JM. Analysis of Fc $\gamma$ receptor IIla and lla polymorphisms: lack of correlation with outcome in trastuzumabtreated breast cancer patients. Clin Cancer Res. 2012;18:3478-86.

19. Miller SA, Dykes DD, Polesky HF. A simple salting out procedure for extracting DNA from human nucleated cells. Nucleic Acids Res. 1988;16:1215.

20. Vilches C, Castaño J, Muñoz P, Peñalver J (2008) Simple genotyping of functional polymorphisms of the human immunoglobulin $G$ receptors CD16A and CD32A: a reference cell panel. Tissue Antigens 71:242-246

\section{(Erratum. In: Tissue Antigens 2008;7:2605)}

21. Zocchi MR, Catellani S, Canevali P, Tavella S, Garuti A, Villaggio B, Zunino A, Gobbi M, Fraternali-Orcioni G, Kunkl A, Ravetti JL, Boero S, Musso A, Poggi A. High ERp5/ADAM10 expression in lymph node microenvironment and impaired NKG2D ligands recognition in Hodgkin lymphomas. Blood. 2012;119:1479-89.

22. Alizadeh BZ, Broen J, Rueda B, Hesselstrand R, Wuttge D, Simeon C, OrtegoCenteno N, Gonzalez-Gay MA, Pros A, Herrick A, Worthington J, Denton C, Fonseca C, Riemekasten G, Vonk MC, van den Hoogen F, Guiducci S, Matucci-Cerinic M, Scorza R, Beretta L, Airó P, Coenen M, Martin J, Koeleman BP, Radstake TR. EUSTAR: functional variants of Fc gamma receptor (FCGR2A) and FCGR3A are not associated with susceptibility to systemic sclerosis in a large European Study (EUSTAR). J Rheumatol. 2010;37:1673-9. 
23. Collins DM, O'Donovan N, McGowan PM, O'Sullivan F, Duffy MJ, Crown J. Trastuzumab induces antibody-dependent cell-mediated cytotoxicity (ADCC) in HER-2-non-amplified breast cancer cell lines. Ann Oncol. 2012;23:1788-95.

24. Subik K, Lee JF, Baxter L, Strzepek T, Costello D, Crowley P, Xing L, Hung MC, Bonfiglio T, Hicks DG, Tang P. The Expression Patterns of ER, PR, HER2 CK5/6, EGFR, Ki-67 and AR by Immunohistochemical Analysis in Breast Cancer Cell Lines. Breast Cancer (Auckl). 2010;4:35-41.

25. Merlin JL, Barberi-Heyob M, Bachmann N. In vitro comparative evaluation of trastuzumab (Herceptin) combined with paclitaxel (Taxol) or docetaxel (Taxotere) in HER2-expressing human breast cancer cell lines. Ann Oncol. 2002;13:1743-8.

26. Vogel CL, Cobleigh MA, Tripathy D, Gutheil JC, Harris LN, Fehrenbacher L, Slamon DJ, Murphy M, Novotny WF, Burchmore M, Shak S, Stewart SJ, Press M. Efficacy and safety of trastuzumab as a single agent in first-line treatment of HER2-overexpressing metastatic breast cancer. J Clin Oncol. 2002;20:719-26.

27. Falls R, Marcom PK, Gelman R, Winer EP. Trastuzumab plus vinorelbine or taxane chemotherapy for HER2-overexpressing metastatic breast cancer: the trastuzumab and vinorelbine or taxane study. Cancer. 2007;110:965-72.

28. Robert N, Leyland-Jones B, Asmar L, Belt R, llegbodu D, Loesch D, Raju R, Valentine E, Sayre R, Cobleigh M, Albain K, McCullough C, Fuchs L, Slamon D. Randomized phase III study of trastuzumab, paclitaxel, and carboplatin compared with trastuzumab and paclitaxel in women with HER-2-overexpressing metastatic breast cancer. J Clin Oncol. 2006;24:2786-92.

29. Oakman C, Pestrin M, Zafarana E, Cantisani E, Di Leo A. Role of lapatinib in the first-line treatment of patients with metastatic breast cancer. Cancer Manag Res. 2010;2:13-25.
30. Brown-Glaberman U, Dayao Z, Royce M. HER2-targeted therapy for earlystage breast cancer: a comprehensive review. Oncology (Williston Park). 2014;28:281-9.

31. Valabrega G, Montemurro F, Aglietta M. Trastuzumab: mechanism of action, resistance and future perspectives in HER2-overexpressing breast cancer. Ann Oncol. 2007;18:977-84.

32. Roca L, Diéras V, Roché H, Lappartient E, Kerbrat P, Cany L, Chieze S, Canon JL, Spielmann M, Penault-Llorca F, Martin AL, Mesleard C, Lemonnier J, de Cremoux P. Correlation of HER2, FCGR2A, and FCGR3A gene polymorphisms with trastuzumabrelated cardiac toxicity and efficacy in a subgroup of patients from UNICANCER-PACS 04 trial. Breast Cancer Res Treat. 2013;139:789-800.

33. Yoon S, Lee MY, Park SW, Moon JS, Koh YK, Ahn YH, Park BW, Kim KS. Up-regulation of acetyl-CoA carboxylase alpha and fatty acid synthase by human epidermal growth factor receptor 2 at the translational level in breast cancer cells. J Biol Chem. 2007;282:26122-31.

34. Beano A, Signorino E, Evangelista A, Brusa D, Mistrangelo M, Polimeni MA, Spadi R, Donadio M, Ciuffreda L, Matera L. Correlation between NK function and response to trastuzumab in metastatic breast cancer patients. J Transl Med. 2008;6:25.

35. Petricevic B, Laengle J, Singer J, Sachet M, Fazekas J, Steger G, Bartsch R, Jensen-Jarolim E, Bergmann M. Trastuzumab mediates antibody-dependent cell-mediated cytotoxicity and phagocytosis to the same extent in both adjuvant and metastatic HER2/neu breast cancer patients. J Transl Med. 2013;11:307-11.

36. Lee HJ, Seo AN, Kim EJ, Jang MH, Suh KJ, Ryu HS, Kim YJ, Kim JH, Im SA, Gong G, Jung KH, Park IA, Park SY. HER2 heterogeneity affects trastuzumab responses and survival in patients with HER2-positive metastatic breast cancer. Am J Clin Pathol. 2014;142:755-66.

\section{Submit your next manuscript to BioMed Central and take full advantage of:}

- Convenient online submission

- Thorough peer review

- No space constraints or color figure charges

- Immediate publication on acceptance

- Inclusion in PubMed, CAS, Scopus and Google Scholar

- Research which is freely available for redistribution

Submit your manuscript at

www.biomedcentral.com/submit

C Biomed Central 